\title{
Ninth grade school performance in Danish childhood cancer survivors
}

\author{
Klaus Kaae Andersen ${ }^{*}, 1$, Anne Katrine Duun-Henriksen ${ }^{1}$, Marie Hoffmann Frederiksen ${ }^{1}$ \\ and Jeanette Falck Winther ${ }^{2}$ \\ ${ }^{1}$ Unit of Statistics, Danish Cancer Society Research Center, Strandboulevarden 49, Copenhagen 2100, Denmark and ${ }^{2}$ Unit of \\ Cancer Survivorship, Childhood Cancer Survivorship Research Group, Danish Cancer Society Research Center, Strandboulevarden 49, \\ Copenhagen 2100, Denmark
}

Background: Childhood cancer survivors can experience learning problems resulting in lower-than-expected attained education as adults. It is unclear whether learning problems manifest already during adolescence.

Methods: We analysed nationwide Danish registries on school grades for Danish children during 2001-2014. Applying a matched design we compared grades of childhood cancer survivors to children without cancer at ninth grade. We estimated grade differences by subject and its correlation to cancer site and age at diagnosis. The available statistical precision allowed for an analysis of more rare cancer sites.

Results: The total study population was 793332 children (mean age 15.24 years and $49.7 \%$ girls), of whom 1320 were childhood cancer survivors. Lower rank grades were seen in children with cancer in all school subjects but differed substantially according to cancer site. Most affected were survivors of central nervous system (CNS) tumours, neuroblastoma, lymphoma, leukaemia, other malignant neoplasm and germ-cell tumours. Survivors from other cancer types did not obtain lower grades. Lower rank grades were associated with young age at diagnosis.

Conclusions: The effect of childhood cancer differed substantially between cancer sites. The largest effect was among survivors of CNS tumours and leukaemia diagnosed at a young age, suggesting an association with radiation therapy. However, the majority of cancer survivors fare well. Increasing awareness on children affected by cancer and special accommodations may help maximise the learning potential of those most affected.

Childhood cancer survival rates in Europe have increased markedly during the past decades, primarily related to advances in treatment (Gatta et al, 2005). In Denmark 5-year survival is now exceeding $80 \%$ (Gatta et al, 2014). Along with improved survival, awareness is turning towards understanding long-term physical and psychological adverse effects (Barrera et al, 2005). Learning problems present an important adverse effect of childhood cancer, which gives rise to concern and may affect school performance and thus educational level. A good education is pivotal to good living standards and prosperity, both for the individual and for the society as such, and should be a marker of successful rehabilitation for childhood cancer patients.

Already in teenage years school performance is seen to be a predictor of attained education later in life (Hurre et al, 2006).
Academic achievement is likely to be influenced both by environmental and social factors, including treatment for cancer (Barrera et al, 2005). Therefore, school performance and grades in adolescents could be an important marker on how cancer treatment affects the life of childhood cancer survivors, and an instrument in identifying high-risk survivors who may benefit from early educational rehabilitation (Ach et al, 2013). Recent papers report that adolescent survivors of childhood cancer, especially those with a history of leukaemia, central nervous system (CNS) tumours or neuroblastoma, have lower attained education than survivors from other cancer types (Koch et al, 2004; Lancashire et al, 2010). It has been documented by Schultz et al (2007) that survivors are at increased risk for adverse behavioural and social outcomes, which in turn mediates school performance.

*Correspondence: Dr KK Andersen; E-mail: klaus@cancer.dk

Received 6 September 2016; revised 5 December 2016; accepted 8 December 2016; published online 12 January 2017

(c) 2017 Cancer Research UK. All rights reserved 0007-0920/17 
Not all children with similar diagnoses and treatment have identical neurocognitive outcomes (Askins and Moore, 2008). Several studies find that most survivors are psychologically healthy and report satisfaction with their lives (Zeltzer et al, 2009; Halsey et al, 2011; Kuehni et al, 2012). Results on how age at diagnosis predicts school performance are conflicting. Although several studies find an association with young age at diagnosis, other studies find that risk for poor functional outcome is not limited to survivors' diagnoses in early childhood (Prasad et al, 2015).

We examined ninth grade school grades in Danish childhood cancer survivors who attended public schools during the period 2001-2014. We used nationwide Danish registries on education and cancer, and applied a novel design by comparing grades of childhood cancer survivors to those in children who attended the same school at the same time. This unique design eliminates potential confounding because of differences between schools and socioeconomic background. The statistical precision allowed for an analysis of more rare cancer sites as well as the effect of age at diagnosis. Studying school grades of childhood cancer survivors could be an important addition to our understanding of how cancer survivors fare, especially during adolescence.

\section{MATERIALS AND METHODS}

We included information on grades for all adolescents who attended ninth grade in public schools in Denmark during 20012014. This was achieved by merging nationwide Danish civil registration data (Pedersen, 2011) and cancer registry data (Gjerstorff, 2011) to registries on school grades (Shewbridge et al, 2011). All children were born between 1 January 1982 and 31 December 1998 and attending Danish public schools. The total sample size for the period was 793332 children. The mean age was 15.24 (interquartile range $14.94-15.48$ ) and $49.7 \%$ were girls. An index variable was created for each combination of school and calendar year in order to cluster children who went to the same school at the same time, and to calculate rank-based grades within each cluster. Cases of childhood cancer were identified in the Danish Cancer Registry. The number of cases was 1956. Of these 1496 were alive at the age of 15 . In total, 1320 children could be found in the student registry with information on grades. The discrepancy between the children alive and those with grades recorded was 176 or $11.7 \%$. The majority of these children are believed to attend private schools, which do not report grades, and thus not included. For each child with a previous diagnosis of cancer we furthermore recorded age at diagnosis and cancer site. The main variables of interest were previous diagnosis of cancer (yes/no), and cancer site divided into the following 12 categories according to the childhood cancer classification scheme: leukaemia, lymphomas, CNS tumour, neuroblastoma, retinoblastoma, renal tumour, hepatic tumour, malignant bone tumour, soft-tissue sarcoma, germ-cell tumour, malignant epithelial tumour and other unspecified malignant neoplasm. Age at diagnosis was recorded as a continuous variable going from 0 to 15 . Additional confounders in the analysis were gender and calendar year. The Danish schooling system is described in Supplementary Information I.

We calculated rank-based grades within each school and year for each student in each grade category. Hereby, school grades were made relative to children with the same educational environment, that is, teacher and similar socioeconomic background; hence, these possible confounders were eliminated by design. Furthermore, rank-based grades are robust to changes in the grading system over time as has been the case in Denmark in 2007. For example, if the grade of a child in a subject was calculated to 0.8 , it would mean that the child's grade corresponded to the 80th percentile among children attending the same school that given year.
We included grades for eight categories including grades for the following study subjects (1) Mathematics oral (o) and written (w), (2) Danish (native language) oral, written and spelling, (3) English oral and written and (4) foreign languages (German/French). We also considered grades based on (5) written (w) and (6) oral (o) tests, separately. Finally, we distinguished between whether the grades were obtained by (7) nationwide standardised test with external evaluation or (8) grade based on the performance over the academic year given by the subject teacher.

Statistical methods. Descriptive statistics was reported by means and proportions and stratified by childhood cancer status. Correlation between grade categories was estimated by means of Pearson correlation. We tested whether cancer survivors finished ninth grade at an older age either due to delayed start or absence leave by means of logistic regression. We used multivariable linear regression models to study the association between childhood cancer and the mean rank grade within school and year, while controlling for gender and calendar year. This was done for the overall mean grade and for each grade category (1-8) separately. Owing to the definition of the rank-based grades, which by default has the mean of 0.5 (i.e., 50 percentile), grade categories that deviated statistically from this value were interpreted as being associated with childhood cancer. The association between childhood cancer and rank grades was furthermore studied according to cancer site and age of diagnosis while controlling for age and birth year in a within-cohort analysis of all childhood cancer survivors. The adjusted effect estimates of cancer site and age of diagnosis were presented graphically with the mean estimates and 95\% confidence intervals and compared with the mean rank of children without a previous cancer diagnosis. Standard residual analysis was applied to verify the fit of the applied models. We examined linearity of continuous variables (age at diagnosis and birth year) by comparing nested models with continuous terms included as higher order orthogonal polynomials. We used the statistical software R (R core team, 2016) with packages (Harrel, 2014; Koenker, 2015; Gordon and Lumley, 2015) for data analysis.

\section{RESULTS}

Table 1 shows the characteristics of 1320 Danish childhood cancer survivors and 792012 non-affected Danish school children attending ninth grade in public schools between 2001 and 2014 . The gender distribution did not differ between childhood cancer survivors and the background population $(P=0.11)$. The mean age was slightly higher for childhood cancer survivors $(P<0.001)$, whereas the distribution of birth year between the two groups did not differ $(P=0.06)$. The most common types of cancer among childhood cancer survivors were leukaemia (31.6\%), CNS tumours (20.4\%) and lymphomas (12.0\%). For most cancer sites, more than $90 \%$ of survivors had information on grades available. This proportion corresponds well to the background population where children attending private schools $(\sim 10 \%)$ do not have information on grades in the registries and thus were not included in this study. However, survivors from CNS (72.9\%) and germ-cell tumours $(79.1 \%)$ did less often have information on grades registered. Table 1 also shows the proportion of cancer cases who are at risk, that is, still alive and resident in Denmark, at the age of 15. The proportion was lowest of survivors from neuroblastoma (50.0\%), bone tumours (53.3\%), soft-tissue sarcoma (63.8\%) and CNS (68.7\%), reflecting a selection of the least affected cancer survivors in this study.

Among Danish school children, 5.0\% were at least 1 year older when completing lower secondary school either because of delayed start or absence leave. Among childhood cancer survivors, the equivalent proportion was $7.9 \%$, resulting in an increased relative 
Table 1. Characteristics of the children included in the study stratified by childhood cancer status (background vs childhood cancer survivors)

\begin{tabular}{|c|c|c|c|c|}
\hline Variable & $\begin{array}{l}\text { Background } \\
N=792012\end{array}$ & $\begin{array}{l}\text { Survivors } \\
N=1320\end{array}$ & $\begin{array}{l}\text { Proportion of cancer } \\
\text { survivors with grades }\end{array}$ & $\begin{array}{l}\text { Proportion of cases at } \\
\text { risk in ninth grade }\end{array}$ \\
\hline Age mean (s.d.) & $15.24(0.44)$ & $15.32(0.48)$ & & \\
\hline $\begin{array}{l}\text { Gender (\%) } \\
\text { Male } \\
\text { Female }\end{array}$ & $\begin{array}{l}398168(50.3) \\
393844(49.7)\end{array}$ & $\begin{array}{l}689(52.2) \\
631(47.8)\end{array}$ & & \\
\hline $\begin{array}{c}\text { Birth year }(\%) \\
\text { Before } 1990 \\
(1990,1995) \\
\text { After } 1995\end{array}$ & $\begin{array}{l}284775(36.0) \\
323875(40.9) \\
183362(23.2)\end{array}$ & $\begin{array}{l}503(38.1) \\
498(37.7) \\
319(24.2)\end{array}$ & & \\
\hline $\begin{array}{l}\text { Age at diagnosis (\%) } \\
\text { Between } 0 \text { and } 2 \\
\text { Between } 2 \text { and } 5 \\
\text { Between } 5 \text { and } 10 \\
\text { Between } 10 \text { and } 15\end{array}$ & & $\begin{array}{l}199(15.1) \\
326(24.7) \\
332(25.2) \\
463(35.1)\end{array}$ & & \\
\hline $\begin{array}{l}\text { Cancer site } \\
\text { Leukaemia } \\
\text { Lymphomas } \\
\text { CNS tumour } \\
\text { Neuroblastoma } \\
\text { Retinoblastoma } \\
\text { Renal tumour } \\
\text { Hepatic tumour } \\
\text { Bone tumour } \\
\text { Soft tissue sarcoma } \\
\text { Germ-cell tumour } \\
\text { Malignant epithelial tumour } \\
\text { Other malignant neoplasm }\end{array}$ & & $\begin{array}{c}417(31.6) \\
158(12.0) \\
269(20.4) \\
54(4.1) \\
55(4.2) \\
75(5.7) \\
14(1.1) \\
62(4.7) \\
70(5.3) \\
38(2.9) \\
93(7.0) \\
15(1.1)\end{array}$ & \begin{tabular}{c|}
96.3 \\
94.6 \\
72.9 \\
100 \\
100 \\
93.4 \\
93.3 \\
100 \\
94.5 \\
79.1 \\
97.9 \\
93.7
\end{tabular} & $\begin{array}{l}77.2 \\
87.4 \\
68.7 \\
50.0 \\
98.2 \\
87.0 \\
68.2 \\
53.3 \\
63.8 \\
80.0 \\
92.2 \\
88.9\end{array}$ \\
\hline
\end{tabular}

Table 2. The mean of rank grades by grade categories, and Pearson correlation between grade categories for both background and survivors

\begin{tabular}{|c|c|c|c|c|c|c|c|c|}
\hline \multicolumn{4}{|c|}{ Mean rank grades } & \multicolumn{5}{|c|}{ Correlation between independent grade categories (background/survivors) } \\
\hline All subjects & 0.50 & 0.48 & 0.002 & & & & & \\
\hline Danish o/w & 0.50 & 0.48 & 0.012 & & $0.73 / 0.72$ & $0.69 / 0.66$ & & \\
\hline English o/w & 0.50 & 0.48 & 0.004 & & & $0.59 / 0.55$ & & \\
\hline Teacher evaluation & 0.50 & 0.47 & 0.001 & & & & & \\
\hline Written & 0.50 & 0.48 & 0.007 & & & & & $0.85 / 0.84$ \\
\hline Oral & 0.50 & 0.48 & 0.015 & & & & & \\
\hline
\end{tabular}

risk OR of 1.63 (CI: 1.34-2.00), with survivors of CNS tumours (9.7\%), lymphomas $(9.5 \%)$, retinoblastoma $(9.3 \%)$ and leukaemia $(8.8 \%)$ being those who most often experienced a delay in passing the ninth grade exam.

Table 2 shows the estimated mean rank grade for each school subject category among childhood cancer survivors and Danish school children in general. Compared with the background population, childhood cancer survivors had statistically significant lower rank grades in all grade categories $(P<0.05)$ within the range of 2-3 percentiles deficit for all grade categories. Furthermore, the table also shows the correlation between grade categories for the background population and survivors. The association between grade categories for survivors was similar to that in the background population. The estimated correlation was moderate to high between independent subjects, with Pearson correlation ranging from 0.57 to 0.69 . The correlation between oral and written grades and between national tests and teacher evaluations was both high, with estimates of 0.85 and 0.86 , respectively.

Lower grades for both combined and specific grade categories were consistently seen among survivors of CNS tumours (44 percentile), neuroblastoma and lymphoma (45 percentile), leukaemia (47 percentile), other (unspecified) malignant neoplasm (43 percentile) and germ-cell tumours (48 percentile), whereas survivors of remaining types of solid tumours constituting $28 \%$ of all survivors did not obtain lower grades than Danish children in general, all having point estimates close the 50th percentile (Table 3). Overall, lower grades were seen in survivors diagnosed below the age of $6(P<0.05)$, that is, cancer in pre-school children, but not in those diagnosed in older age groups. No difference between birth cohorts was observed (not shown). No systematic 
Table 3. The mean rank grades by cancer site, age at diagnosis and birth year for childhood cancer survivors

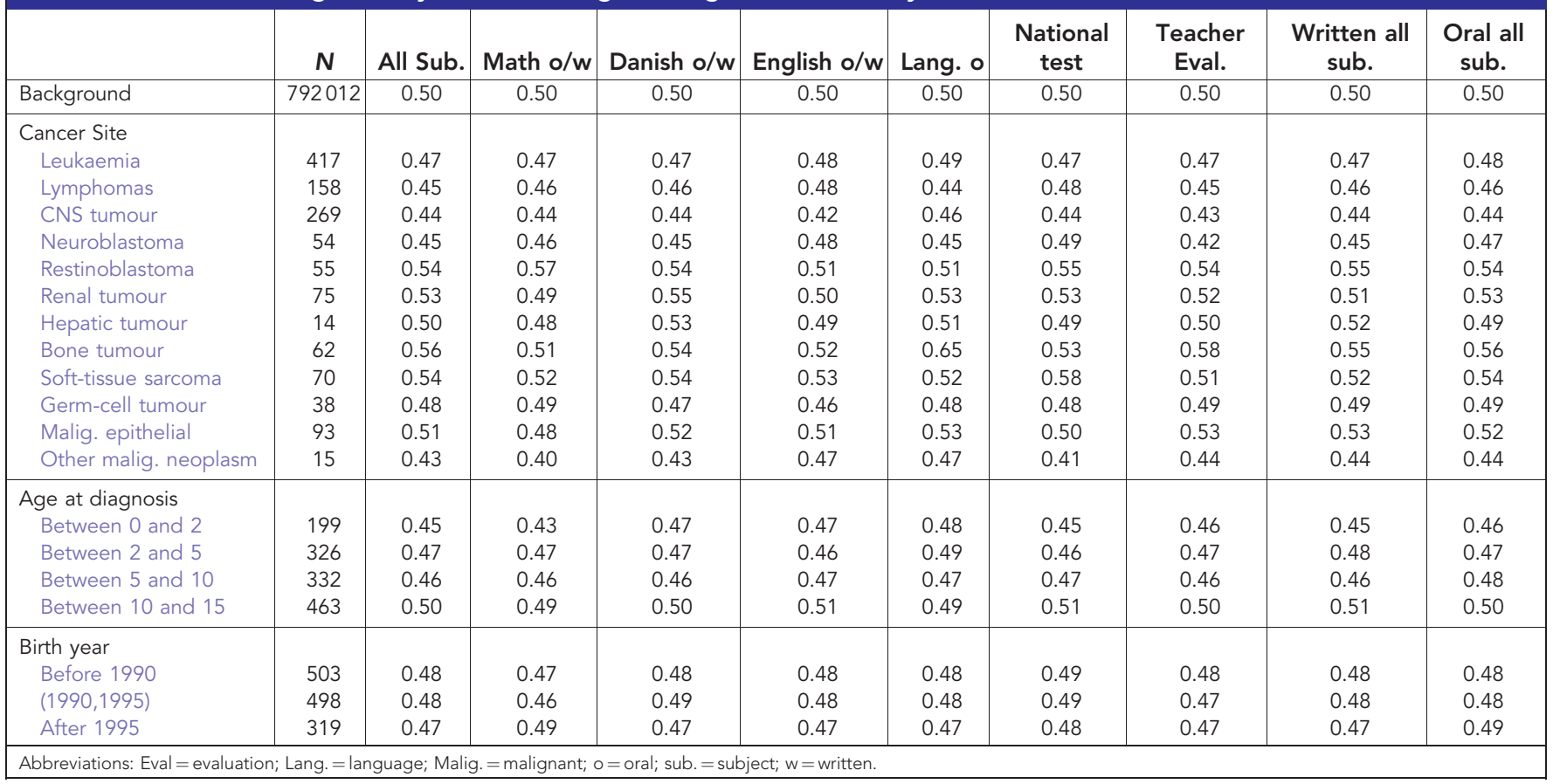

patterns were observed for specific grade categories $(P>0.05$; not shown). When a reduction was seen in the overall rank grades, a similar pattern was seen in all grade categories 1-8.

In the multivariable analysis adjusting for age at diagnosis, gender and birth year, significant reductions in rank grades were seen in survivors of the most common sites: leukaemia, lymphomas and CNS tumours (Figure 1). For most cancer sites the reduction had a tendency to be stronger in girls, although not statistically significant.

The estimated rank grade for all grades combined for the three major diagnostic groups and remaining childhood cancer types combined by age at diagnosis is shown in Figure 2. Young age at diagnosis, especially below the age of 6 , was a strong predictor especially for survivors of CNS tumours, with an average rank percentile close to $35 \%$ but also for leukaemia survivors. Age at diagnosis, however, was not related to rank grades for other cancer sites.

Finally, heterogeneity in rank grades in different school subjects among childhood cancer survivors by age at diagnosis was evaluated by estimating the 20th and 80th percentile in Danish, Mathematics, English and all subjects. Largest heterogeneity compared with children in the background population was seen in English and Mathematics, and less in Danish and rank grades overall. Most marked was the effect in the lower 20th percentile in comparison with the 80th percentile and in survivors from leukaemia and CNS tumours at a young age at diagnosis. The differences indicated that only a minor proportion of children with childhood cancer have impaired scholastic achievements, and in the lowest percentiles, whereas most survivors fare well.

\section{DISCUSSION}

Our primary finding was that the effect of childhood cancer on school-grade performance in adolescents differed substantially between cancer sites. Lower rank grades overall were seen among survivors of CNS tumours, neuroblastoma, lymphoma, leukaemia, germ-cell tumours and other unspecified malignant neoplasm.
The results were consistent for the grade categorisations in our study; we did not identify school subjects wherein survivors were especially affected, although a tendency towards more heterogeneity in rank grades in Mathematics and English among survivors of childhood cancer was observed. Among survivors from leukaemia and CNS tumour there was a clear effect of age at diagnosis, with largest learning impairment in those diagnosed at a young age (pre-school). No association with age at diagnosis was seen among survivors from lymphoma. These results are consistent with several other studies (Copeland et al, 1985; Langeveld et al, 2003; Harila-Saari et al, 2007; Lahteenmaki et al, 2007, 2008; Lancashire et al, 2010). Not surprisingly, childhood cancer survivors were at an increased risk of completing the ninth grade at an older age, either because of a delayed school start or because of absence from school.

More unexpectedly, we found that survivors of retinoblastoma, renal tumours, hepatic tumours, bone tumours, soft-tissue sarcomas and malignant epithelial tumours did not obtain lower rank grades than children without cancer. In fact, point estimates of rank grades were higher compared with the background population among survivors of retinoblastoma, renal tumours, hepatic tumours, bone tumours, soft-tissue sarcomas and malignant epithelial tumours, although not statistically significant. A plausible explanation to this finding is that our study primarily included a selected group of survivors being those least affected; that is, all children had to survive until the age of 15 and had to be able to attend public schools to be included in this study. For example, only $\sim 50 \%$ of all children diagnosed with neuroblastoma or bone tumours were included. An additional explanation for survivors of solid tumours such as retinoblastoma and renal tumours (mainly Wilms tumour survivors) with an inclusion similar to that of the background population might indicate that the treatment for these cancer types do not affect learning and that the schooling system in Denmark is capable of meeting the educational needs of these children.

Certain chemotherapy drugs, surgery or radiation to the head or whole body can directly induce learning problems (Langeveld et al, 2003; Williams et al, 2016). Furthermore, cancer treatment can result in physical disability, lower energy levels, worse hearing or 


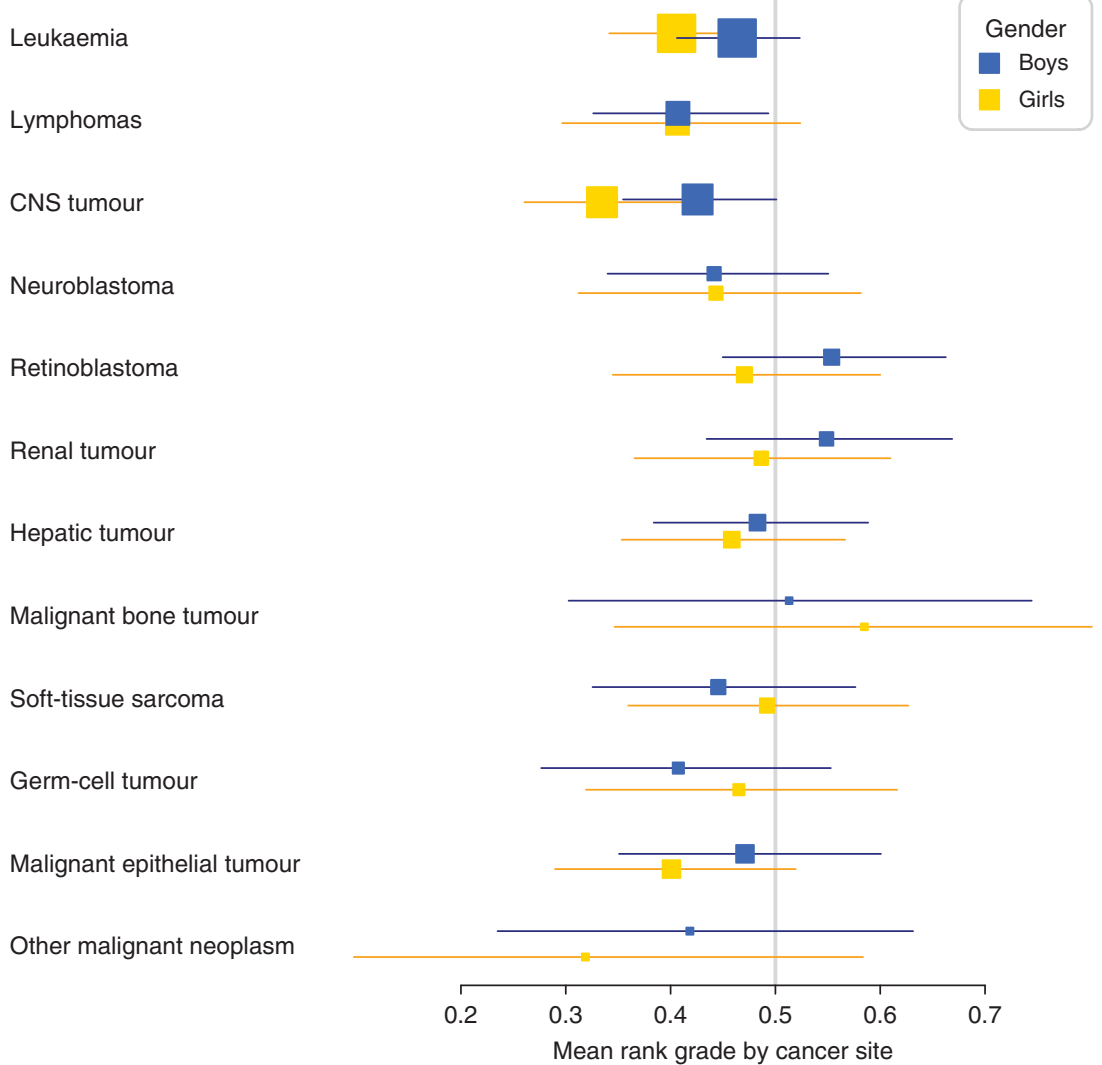

Figure 1. Effect on overall rank grade by gender and cancer site. The vertical line at $50 \%$ represents no effect.
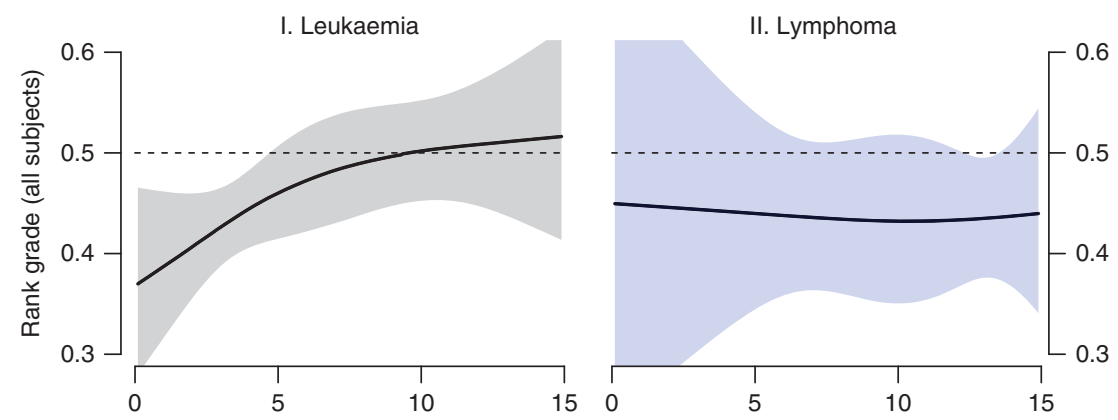

III. CNS
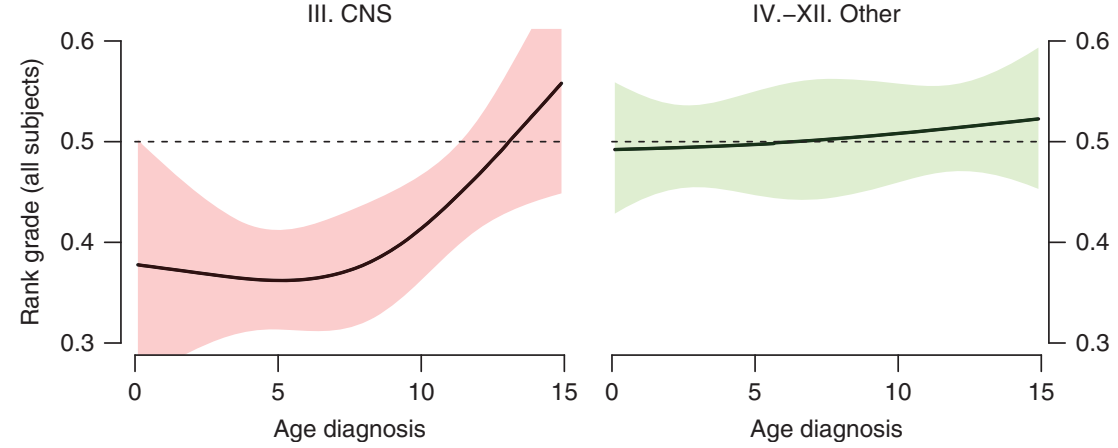

Figure 2. Effect on overall rank grade by age at diagnosis and cancer site. Effect on overall rank grade by age at diagnosis for (I) leukemia (top left); (II) lymphoma (top right; (III) CNS (bottom left) and (IV-XII) other cancer sites (bottom right). The horizontal line at 50\% represents no effect.

vision, all of which can affect learning and concentration ability (Copeland et al, 1985; Buizer et al, 2005; Mabbott et al, 2011). The overview by Schwartz (1999) reports that cognitive deficits are common. This results in poor academic achievement, including difficulties in reading, language and arithmetic. The deficits may arise from impairment of attention capabilities, memory and visual perceptual motor skills, and over time, intellectual growth begins to lag behind the expected course. A main limitation of our study was that we did not have access to actual treatment, and thus we do not have the possibility to regress treatment on rank grades. However, 
our results confirm those of earlier studies reporting an effect among survivors of CNS tumours and leukaemia (Harila-Saari et al, 2007; Lahteenmaki et al, 2007; Lancashire et al, 2010). Especially among survivors of CNS tumours the effect was pronounced in all subjects with a mean grade rank between 42 and 46. These findings suggest that impaired learning may be related to treatment by radiation therapy, as other studies have linked radiation treatment to cognitive difficulties (Winterling et al, 2015; Williams et al, 2016). Although plausible, we could not confirm this hypothesis, as we do not have information on specific treatment of the cancer survivors. Furthermore, we did not investigate whether factors such as comorbidity, impairment of hearing and vision or other psychosocial late effects mediated the effect of childhood cancer on rank grades. Nor did we have information on whether special education was given and had an effect as this information was only available from the year 2011, and longer follow-up is needed. The above limitations are all unanswered questions and topics for future and ongoing research.

The nationwide Danish study by Koch et al (2004) and the British nationwide study by Lancashire et al (2010) both report lower-than-expected educational attainment in survivors from CNS and leukaemia. Our results show that an effect for these groups is seen already in adolescence. This supports the argument for that detailed educational support, and implementation of regular cognitive assessment may be indicated for some groups to maximise long-term function. In this light our study leads to other research questions to be addressed.

The most important strength of the study presented here includes the availability to nationwide and accurate data from a heterogeneous population of adolescents. We applied a unique design where the rank grade of each child was calculated within the same school and year, thus eliminating sociodemographic differences. We believe that this design is preferable to other studies documented previously in the literature on learning difficulties among childhood cancer survivors, especially to those based on retrospective sampling and possible residual confounding because of unmeasured confounders and non-matched comparison groups. The use of rank grades is likely a more precise instrument to detect even small effects compared with attained education. Only a few other published studies have been able to address the impact of childhood cancer on school performance measured by grades in adolescents, documenting impaired learning among survivors of leukaemia, CNS and Wilms tumour patients, in particular among girls (Harila-Saari et al, 2007; Lahteenmaki et al, 2007, 2008). These studies, however, have been limited to specific diagnostic groups, crude matching, possible residual confounding and limited statistical power. Another limitation in the existing literature includes small sample size of patients of either a single diagnostic group or a combination of all cancer types together (Barrera et al, 2005). A few larger studies have been able to provide useful insights, see Mitby et al (2003). These studies, however, are based on self-reported questionnaires and comparison groups made up by siblings, who themselves might be affected by having a sibling with cancer (Hudson et al, 2003; Schultz et al, 2007; Kuehni et al, 2012). Few studies have been able to establish comparison groups of individuals without cancer, and most have included only adult survivors (Koch et al, 2004; Barrera et al, 2005; Lancashire et al, 2010). Including only adult survivors limits the possibility of identifying high-risk childhood cancer survivors who may benefit from early educational rehabilitation in teenage years.

We do not have sufficient follow-up data to evaluate how school grades correlate to attained education in adult life and career paths for childhood cancer survivors. However, a previous study by Kern and Friedman (2008) has shown that early educational success is a predictor of a lifelong academic achievement. We found a deficit in rank grades on average from 2 to 6 percentile points, but for those most affected, such as survivors of leukaemia or CNS tumours, up to 15 percentile points. Whether this is a large effect or not can be demonstrated by using findings from a study from Finland by Huurre et al (2006), showing that adolescence is an important period for future educational life trajectory. Low school achievement was the strongest predictor of low educational level in adulthood and a strong predictor of attained education. Assuming similar effects as those reported in the Finnish study, we find that a difference in 15 percentile points is associated with an increased risk of $\sim 76 \%$ (CI: $66-89 \%$ ) for not obtaining a higher educational level, whereas a difference in 6 percentile points is associated with an increased risk of $\sim 25 \%$ (CI: 23-29\%). Consequently, those survivors most affected by their cancer have a markedly increased risk of not obtaining a higher educational level-an issue that should be recognised.

Level of educational attainment can be used as a quality-of-life measure, and learning impairment following childhood cancer should have implications for clinicians or policymakers. We find that the majority of Danish cancer survivors fare as well as the children without a history of cancer, but that an important subgroup is affected. Increasing awareness on children affected by cancer and special accommodations or services may help maximise the learning potential of those most affected. Our findings suggest targeting interventions for groups at highest risk of being affected.

\section{ACKNOWLEDGEMENTS}

This work was supported by Helsefonden, grant no. 16-B-0024.

\section{CONFLICT OF INTEREST}

The authors declare no conflict of interest.

\section{REFERENCES}

Ach E, Gerhardt CA, Barrera M, Kupst MJ, Meyer EA, Patenaude AF, Vannatta K (2013) Family factors associated with academic achievement deficits in pediatric brain tumor survivors. Psychooncology 22: 1731-1737.

Askins MA, Moore BD (2008) Preventing neurocognitive late effects in childhood cancer survivors. J Child Neurol 23: 1160-1171.

Barrera M, Shaw AK, Speechley KN, Maunsell E, Pogany L (2005) Educational and social late effects of childhood cancer and related clinical, personal, and familial characteristics. Cancer 104: 1751-1760.

Buizer AI, de Sonneville LM, van den Heuvel-Eibrink MM, Veerman AJ (2005) Chemotherapy and attentional dysfunction in survivors of childhood acute lymphoblastic leukemia: effect of treatment intensity. Pediatr Blood Cancer 45: 281-290.

Copeland DR, Fletcher JM, Pfefferbaum-Levine B, Jaffe N, Ried H, Maor M (1985) Neuropsychological sequelae of childhood cancer in long-term survivors. Pediatrics 75: 745-753.

Gatta G, Botta L, Rossi S, Aareleid T, Bielska-Lasota M, Clavel J, Dimitrova N, Jakab Z, Kaatsch P, Lacour B, Mallone S, Marcos-Gragera R, Minicozzi P, Sánchez-Pérez M), Sant M, Santaquilani M, Stiller C, Tavilla A, Trama A, Visser O, Peris-Bonet R, EUROCARE Working Group (2014) Childhood cancer survival in Europe 1999-2007: results of EUROCARE-5-a population-based study. Lancet Oncol 15: 35-47.

Gatta G, Capocaccia R, Stiller C, Kaatsch P, Berrino F, Terenziani M (2005) Childhood cancer survival trends in Europe: a EUROCARE Working Group study. J Clin Oncol 23: 3742-3751.

Gjerstorff ML (2011) The Danish Cancer Registry. Scand J Public Health 39: $42-45$.

Gordon M, Lumley T (2015) forestplot: Advanced Forest Plot Using 'grid' Graphics. R package version 1.1.

Halsey C, Buck G, Richards S, Vargha-Khadem F, Hill F, Gibson B (2011) The impact of therapy for childhood acute lymphoblastic leukaemia on intelligence quotients; results of the risk-stratified randomized central nervous system treatment trial MRC UKALL XI, J. Hematol Oncol 4: 42. 
Harila-Saari AH, Lahteenmaki PM, Pukkala E, Kyyronen P, Lanning M, Sankila R (2007) Scholastic achievements of childhood leukemia patients: a nationwide, register-based study. J Clin Oncol 25: 3518-3524.

Harrel Jr FH (2014) rms: regression modeling strategies. R Package Version 4: 2-1.

Hudson MM, Mertens AC, Yasui Y, Hobbie W, Chen H, Gurney JG, Yeazel M, Recklitis CJ, Marina N, Robison LR, Oeffinger KC (2003) Health status of adult long-term survivors of childhood cancer: a report from the Childhood Cancer Survivor Study. JAMA 290: 1583-1592.

Huurre T, Aro H, Rahkonen O, Komulainen E (2006) Health, lifestyle, family and school factors in adolescence: predicting adult educational level. Educ Res 48: 4-51.

Kern ML, Friedman HS (2008) Early educational milestones as predictors of lifelong academic achievement, midlife adjustment, and longevity. J Appl Dev Psychol 30: 419-430.

Koch SV, Kejs AM, Engholm G, Johansen C, Schmiegelow K (2004) Educational attainment among survivors of childhood cancer: a population-based cohort study in Denmark. Br J Cancer 91: 923-928.

Koenker R (2015) quantreg: Quantile Regression. R package version 5.11.

Kuehni CE, Strippoli MO, Rueegg P, Rebholz CE, Bergstraesser E, Grotzer M, von der Weid NX, Michel G, Swiss Pediatric Oncology Group (SPOG) (2012) Educational achievement in Swiss childhood cancer survivors compared with the general population. Cancer 118: 1439-1449.

Lancashire ER, Frobisher C, Reulen RC, Winter DL, Glaser A, Hawkins MM (2010) Educational attainment among adult survivors of childhood cancer in Great Britain: a population-based cohort study. J Natl Cancer Inst 102: 254-270.

Lahteenmaki PM, Harila-Saari A, Pukkala EI, Kyyronen P, Salmi TT, Sankila R (2007) Scholastic achievements of children with brain tumors at the end of comprehensive education: a nationwide, register-based study. Neurology 69: 296-305.

Lahteenmaki PM, Sankila R, Pukkala E, Kyyronen P, Harila-Saari A (2008) Scholastic achievement of children with lymphoma or Wilms tumor at the end of comprehensive education-a nationwide, register-based study. Int J Cancer 123: 2401-2405.

Langeveld NE, Ubbink MC, Last BF, Grootenhuis MA, Voute PA, De Haan RJ (2003) Educational achievement, employment and living situation in long-term young adult survivors of childhood cancer in the Netherlands. Psychooncology 12: 213-225.

Mabbott DJ, Monsalves E, Spiegler BJ, Bartels U, Janzen L, Guger S, Laperriere N, Andrews N, Bouffet E (2011) Longitudinal evaluation of neurocognitive function after treatment for central nervous system germ cell tumors in childhood. Cancer 117: 5402-5411.
Mitby PA, Robison LL, Whitton JA, Zevon MA, Gibbs IC, Tersak JM, Meadows AT, Stovall M, Zeltzer LK, Mertens AC (2003) Utilization of special education services and educational attainment among long-term survivors of childhood cancer: a report from the Childhood Cancer Survivor Study. Cancer 97: 1115-1126.

Pedersen CB, The Danish Civil Registration System (2011) Scand J Public Health 39: 22-25.

Prasad PK, Hardy KK, Zhang N, Edelstein K, Srivastava D, Zeltzer L, Stovall M, Seibel NL, Leisenring W, Armstrong GT, Robison LL, Krull K (2015) Psychosocial and neurocognitive outcomes in adult survivors of adolescent and early young adult cancer: a report from the Childhood Cancer Survivor Study. J Clin Oncol 33: $2545-2552$.

R Core Team (2016) R: A Language and Environment for Statistical Computing. R Foundation for Statistical Computing: Vienna, Austria.

Schultz KA, Ness KK, Whitton J, Recklitis C, Zebrack B, Robison LL, Zeltzer L, Mertens AC (2007) Behavioral and social outcomes in adolescent survivors of childhood cancer: a report from the childhood cancer survivor study. J Clin Oncol 25: 3649-3656.

Schwartz CL (1999) Long-term survivors of childhood cancer: the late effects of therapy. Oncologist 4: 45-54.

Shewbridge C, Jang E, Matthews P, Santiago P (2011) 'OECD Reviews of Evaluation and Assessment in Education'. OECD.

Williams NL, Rotondo RL, Bradley JA, Pincus DW, Fort JA, Wynn T, Morris CG, Mendenhall NP, Indelicato DJ (2016) Late effects after radiotherapy for childhood low-grade glioma. Am J Clin Oncol; e-pub ahead of print 22 January 2016.

Winterling J, Jervaeus A, Sandeberg M, Johansson E, Wettergren L (2015) Perceptions of school among childhood cancer survivors: a comparison with peers. J Pediatr Oncol Nurs 32: 201-208.

Zeltzer LK, Recklitis C, Buchbinder D, Zebrack B, Casillas J, Tsao JC, Lu Q, Krull K (2009) Psychological status in childhood cancer survivors: a report from the Childhood Cancer Survivor Study. J Clin Oncol 27: 2396-2404.

This work is published under the standard license to publish agreement. After 12 months the work will become freely available and the license terms will switch to a Creative Commons AttributionNonCommercial-Share Alike 4.0 Unported License.

Supplementary Information accompanies this paper on British Journal of Cancer website (http://www.nature.com/bjc) 